\title{
Molecular analysis suggests that Namibian cheetahs (Acinonyx jubatus) are definitive hosts of a so far undescribed Besnoitia species
}

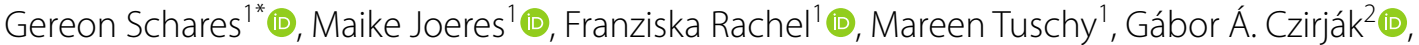 \\ Pavlo Maksimov ${ }^{1}$ (D) Franz J. Conraths ${ }^{1}\left[\right.$ and Bettina Wachter ${ }^{3}$ (D)
}

\begin{abstract}
Background: Besnoitia darlingi, B. neotomofelis and B. oryctofelisi are closely related coccidian parasites with felids as definitive hosts. These parasites use a variety of animal species as intermediate hosts. North American opossums (Didelphis virginiana), North American southern plains woodrats (Neotoma micropus) and South American domestic rabbits (Oryctolagus cuniculus) are intermediate hosts of B. darlingi, B. neotomofelis and B. oryctofelisi, respectively. Based on conserved regions in the internal transcribed spacer-1 (ITS1) sequence of the ribosomal DNA (rDNA), a realtime PCR for a sensitive detection of these Besnoitia spp. in tissues of intermediate hosts and faeces of definitive hosts has recently been established. Available sequence data suggest that species such as B. akodoni and B. jellisoni are also covered by this real-time PCR. It has been hypothesised that additional Besnoitia spp. exist worldwide that are closely related to B. darlingi or B. darlingi-like parasites (B. neotomofelis, B. oryctofelisi, B. akodoni or B. jellisoni). Also related, but not as closely, is B. besnoiti, the cause of bovine besnoitiosis.
\end{abstract}

Methods: Faecal samples from two free-ranging cheetahs (Acinonyx jubatus) from Namibia that had previously tested positive for coccidian parasites by coproscopy were used for this study. A conventional PCR verified the presence of coccidian parasite DNA. To clarify the identity of these coccidia, the faecal DNA samples were further characterised by species-specific PCRs and Sanger sequencing.

Results: One of the samples tested positive for $B$. darlingi or B. darlingi-like parasites by real-time PCR, while no other coccidian parasites, including Toxoplasma gondii, Hammondia hammondi, H. heydorni, B. besnoiti and Neospora caninum, were detected in the two samples. The rDNA of the B. darlingi-like parasite was amplified and partially sequenced. Comparison with existing sequences in GenBank revealed a close relationship to other Besnoitia spp., but also showed clear divergences.

Conclusions: Our results suggest that a so far unknown Besnoitia species exists in Namibian wildlife, which is closely related to B. darlingi, B. neotomofelis, B. oryctofelisi, B. akodoni or B. jellisoni. The cheetah appears to be the definitive host of this newly discovered parasite, while prey species of the cheetah may act as intermediate hosts.

Keywords: Besnoitia spp., Namibia, Real-time PCR, Metatheria, Eutheria, Placental mammals, Marsupial mammals, Phylogeny, Acinonyx jubatus

\footnotetext{
*Correspondence: gereon.schares@fli.de

${ }^{1}$ Institute of Epidemiology, Friedrich-Loeffler-Institut, Federal Research Institute for Animal Health, Südufer 10, 17493 Greifswald-Insel Riems, Germany

Full list of author information is available at the end of the article
}

\section{Background}

Besnoitia darlingi, B. neotomofelis and B. oryctofelisi are closely related coccidian parasites, for which domestic cats have been ascertained as definitive hosts [1-4]. The 
bobcat (Lynx rufus) has been identified as the definitive host of B. darlingi in the wild [5]. Besnoitia darlingi uses a marsupial, the North American opossum (Didelphis virginiana), as its intermediate host [5]. In contrast, $B$. neotomofelis and B. oryctofelisi have been described in placental mammals, i.e. in the North American southern plains woodrat (Neotoma micropus) and in domestic rabbits from South America (Oryctolagus cuniculus), respectively $[2,4,6]$. Besnoitia akodoni, another closely related Besnoitia species, was described in a placental mammal in South America, i.e. the rodent Akodon montensis, as intermediate host [7]. Another Besnoitia sp., B. jellisoni, was described in the North American white-footed deer mouse (Peromyscus maniculatus) and in three species of kangaroo rats (Dipodomys species) as intermediate hosts $[8,9]$. In contrast to $B$. darlingi, B. neotomofelis, and $B$. oryctofelisi, the definitive hosts of $B$. jellisoni or $B$. akodoni are unknown. Domestic cats, other carnivorous mammals, various birds and snakes have been excluded as final hosts of $B$. jellisoni $[10,11]$. Further reports suggest the presence of similar Besnoitia spp. parasites in New Zealand, Australia, Japan and Kenya [12-15]. Moreover, for B. wallacei, first described on Oahu, Hawaii, in a domestic cat (i.e. its definitive host), experimental studies suggested rodents (mice, rats) as appropriate intermediate hosts [10].

It has therefore recently been argued that other, so far unknown, Besnoitia species may exist in other parts of the world [16]. The high level of conservation in the internal transcribed spacer-1 (ITS1) sequence of the ribosomal DNA (rDNA) among related species of $B$. darlingi and B. darlingi-like species (B. neotomofelis, $B$. oryctofelisi, $B$. akodoni, $B$. jellisoni) was utilised to establish primers and a probe for the detection of such Besnoitia spp. parasites in their intermediate (e.g. rodents, lagomorphs and marsupials) or definitive hosts (e.g. wild felids or canids) [16]. This real-time PCR is not able to detect the Besnoitia spp. of ungulates, i.e. cattle, goats, donkeys and horses, and caribou and reindeer, such as B. besnoiti, B. caprae, B. bennetti and B. tarandi, respectively [16].

Our previous work suggested the presence of Toxoplasma gondii in most of 12 Namibian wildlife species and that of B. besnoiti and Neospora caninum in a few of these same species, including six of suborder Feliformia, four of suborder Caniformia and two of suborder Ruminantia [17]. Felids, including cheetahs (Acinonyx juba$t u s$ ), are known as definitive hosts of $T$. gondii, but for $B$. besnoiti, the causative agent of bovine besnoitiosis, the definitive host is still unknown, although wild felids have been discussed as candidates $[17,18]$. Since morphological identification of coccidian parasites is challenging, we used molecular methods to examine the faeces collected from the ampulla recti of two free-ranging cheetahs for $B$. besnoiti. In a previous study, these two cheetahs had been shown to be positive for coccidian oocysts by coproscopy [19].

\section{Methods \\ DNA extraction}

In this study, we used faecal samples from two freeranging female cheetahs, one sub-adult and one adult, from farmland in central Namibia. The animals had previously tested positive for coccidian parasites by coproscopy [19]. The original and detailed records reported up to 3600 oocysts with an approximate size of $18-22.5 \times 18.0-36.0 \mu \mathrm{m}$ per gram faeces [19]. Coproscopy of the sub-adult and the adult cheetah for the present study revealed 3600 and 50 oocysts with an approximate size of $18.0 \times 18.0 \mu \mathrm{m}$, respectively, per gram faeces, as well as 300 oocysts with an approximate size of $22.5 \times 36.0 \mu \mathrm{m}$ per gram faeces in the adult cheetah (BW and GÁC, unpublished data). Capture and handling of the animals, sample collection, transport and storage has been described previously $[17,19,20]$. The Quick-DNA Fecal/Soil Microbe DNA Miniprep Kit (Zymo Research Europe GmbH, Freiburg, Germany) was used to extract DNA from approximately 200-mg aliquots according to the manufacturer's recommendations. From the faecal sample of the sub-adult female, two aliquots were available, which were independently extracted. Extraction typically yields $100 \mu \mathrm{l}$ DNA per faecal sample [16].

\section{Endpoint PCR}

To test for coccidian parasites, a PCR was performed using the common apicomplexan small subunit ribosomal DNA (18S rDNA) primers COC-1 and COC-2 [21, 22]. Hammondia heydorni DNA was tested using the primers JS4 and JS5 as described [23, 24]. Due to the high level of sequence identity in the rDNA target, the primer pair JS4/JS5 was expected to amplify also DNA of Hammondia triffitae, a coccidian parasite using foxes as definitive hosts [25-27].

For the identification of coccidian parasites by Sanger sequencing, rDNA was amplified by endpoint PCR using primer pairs (Fig. 1) as previously published [23, 28, 29] and listed in Additional file 1: Table S1.

For all PCRs, primers were used at a final concentration of $0.5 \mathrm{mM}$ and dNTPs at a final concentration of $250 \mathrm{mM}$ each (Stratec Molecular GmbH, Berlin, Germany). Taq polymerase (Stratec Molecular $\mathrm{GmbH}$ ) had a final concentration of $1 \mathrm{U} / 25 \mu \mathrm{l}$ using the buffer system supplied with the enzyme. The PCR cycling conditions were: $94{ }^{\circ} \mathrm{C}, 5 \mathrm{~min}$; then $56^{\circ} \mathrm{C} / 1 \mathrm{~min}$ (with $0.5{ }^{\circ} \mathrm{C}$ 


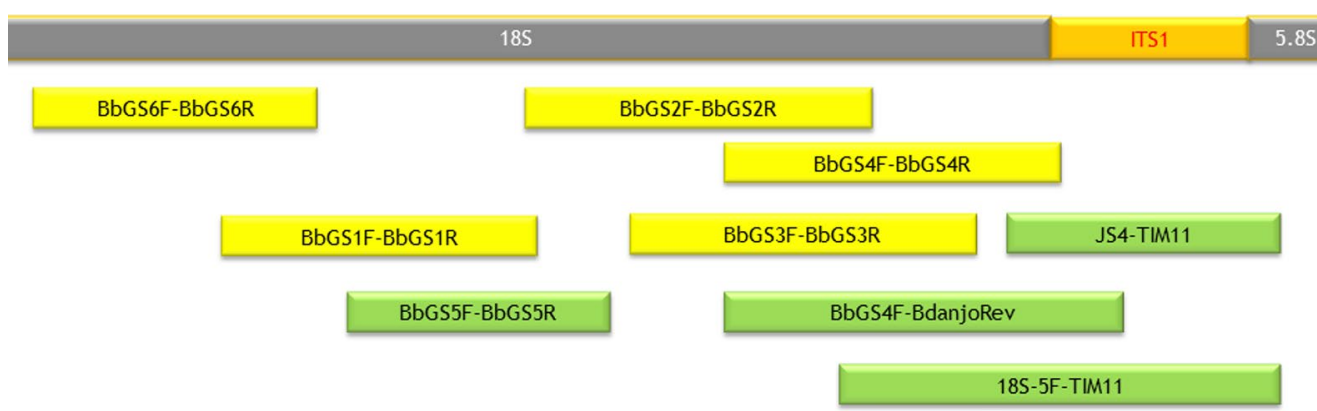

Fig. 1 Overview of PCR fragments and primer names used to assess rDNA sequences of Besnoitia darlingi-like parasites (named "Besnoitia-acinonyx" for this study) and related organisms in faeces of a Namibian cheetah. Green-coloured amplicons revealed sequences closely related to $B$. darlingi-like parasites (Table 1); yellow-coloured amplicons revealed sequences related to additional coccidia (Table 1). Details on primer sequences are given in Additional file 1:Table S1. ITS1 Internal transcribed spacer-1

decrement per cycle after the 1 st cycle), $72{ }^{\circ} \mathrm{C} / 1 \mathrm{~min}$, $94{ }^{\circ} \mathrm{C} / 1 \mathrm{~min}$, for 10 cycles; followed by $51{ }^{\circ} \mathrm{C} / 1 \mathrm{~min}$, $72{ }^{\circ} \mathrm{C} / 1 \mathrm{~min}, 94{ }^{\circ} \mathrm{C} / 1 \mathrm{~min}$, for 40 cycles; and a final incubation at $51{ }^{\circ} \mathrm{C}$ for $1 \mathrm{~min}$ and a final extension at $72{ }^{\circ} \mathrm{C}$ for $5 \mathrm{~min}$.

\section{Real-time PCRs}

Real-time PCRs were used to test for T. gondii, Hammondia hammondi, B. besnoiti, B. darlingi and B. darlingilike parasites or $N$. caninum. Toxoplasma gondii was examined as previously reported targeting the TgREP529 repetitive element $[30,31]$. Hammondia hammondi was diagnosed using a recently published real-time PCR targeting the HhamREP-529 repetitive element [22]. In the case of $B$. besnoiti, a fragment of the ITS1 region in the rDNA was amplified as described (BbRT1; [32]). For $B$. darlingi and $B$. darlingi-like parasite, a recently published real-time PCR designated BdanjoRT1 was applied [16]. For the detection of $N$. caninum DNA, a previously published real-time PCR targeting the Nc5 gene [31, 33] was used.

To monitor the inhibition of the real-time PCRs, a heterologous plasmid with DNA sequences resembling the enhanced green fluorescent protein (EGFP) gene [34] was added to the reaction mix in all real-time PCRs except those for $N$. caninum. The internal control PCR included the primers EGFP1-F, EGFP2-R and the probe EGFP1 [22]. A 712-bp fragment of the EGFP gene was amplified and cloned into the pGEM-Teasy standard cloning vector (Promega, Walldorf, Germany) in reverse orientation to obtain the internal control (IC) DNA (pGEM-EGFP2rev). The amount of the IC DNA added to each reaction was adjusted so that it resulted in a quantification cycle (Cq) value of approximately 32 in the real-time PCR.

Reactions were performed in a final volume of $20 \mu \mathrm{l}$ using a commercial master mix (PerfeCTa MultiPlex
qPCR ToughMix; Quantabio, VWR International, Darmstadt, Germany) and a CFX384 instrument (Biorad Laboratories $\mathrm{GmbH}$, Munich, Germany). Primers and probes were purchased from MWG-Biotech (Ebersberg, Germany). Standard concentrations for primers $(500 \mathrm{nM})$ and probes $(100 \mathrm{nM}$, target specific primers; 160 nM, EGFP1) were used. The cycling conditions in real-time PCR: were $95.0{ }^{\circ} \mathrm{C}, 5 \mathrm{~min}$ (initial denaturation); then $95.0{ }^{\circ} \mathrm{C} / 10 \mathrm{~s}, 60.0{ }^{\circ} \mathrm{C} / 30 \mathrm{~s}$, for 45 cycles. After each cycle, the light emission by the fluorophore was measured. Real-time PCR results were analysed using the CFX manager software version 1.6 (Biorad Laboratories GmbH, Munich, Germany).

\section{Cloning}

For Sanger sequencing of the amplification products, bands of the expected size were excised from agarose gels and purified with a commercial kit (NucleoSpin ${ }^{\circledR}$ Gel and PCR Clean-up; Macherey-Nagel, Düren, Germany), following the manufacturer's instructions. Purified amplification products were then cloned into a commercially available vector $\left(\mathrm{pGEM}^{\circledR}-\mathrm{T}\right.$ Easy Vector System I; Promega, Mannheim, Germany) and used to transform chemically competent Escherichia coli (OneShot TOP10; Thermo Fisher Scientific, Langenselbold, Germany). The transformed E. coli cell were cultivated and the plasmid DNA was subsequently collected using a commercial kit (QIAprep Spin Miniprep Kit; Qiagen, Hilden, Germany) according to the manufacturer's instructions. Sequencing was performed using the BigDye Terminator v1.1 Cycle Seq. Kit (Thermo Fisher Scientific) and passage through NucleoSEQ Columns (Macherey-Nagel) for cleaning up the nucleic acids, in an ABI 3130 capillary sequencer (Thermo Fisher Scientific). 
The forward and reverse sequences were aligned, if necessary trimmed based on primer sequence information, and the consensus sequences for the individual cloned amplification products compared to sequences stored in GenBank, EMBL, DDBJ or RefSeq using BLASTn with standard conditions.

\section{Phylogenetic analysis}

The evolutionary history based on ITS1 rDNA sequences was inferred using the maximum parsimony (MP) method. The number of base substitutions per site between sequences included into the analysis was termed "pairwise distance" or "evolutionary divergence" in the following section. The MP tree was obtained using the subtree-pruning-regrafting algorithm [35] with search level 0 , in which the initial trees were obtained by the random addition of sequences (10 replicates). All codon positions (1st, 2nd, 3rd, noncoding) were included. Evolutionary analyses were conducted in MEGA X [36].

\section{Results}

\section{PCRs for coccidian parasites}

The observed parasitic structures, previously diagnosed microscopically as coccidia [19], were confirmed by a positive reaction in an $18 S$ rDNA-based endpoint COC-1/COC-2 PCR for both samples of the two cheetahs (one sub-adult and one adult female). Species-specific PCRs were negative for $T$. gondii, $H$. hammondi and $B$. besnoiti. The unlikely presence of $N$. caninum or $H$. heydorni was also excluded by real-time or endpoint PCR, respectively. Using a real-time PCR established to detect $B$. darlingi and $B$. darlingi-like parasites [16], we observed a positive signal (Cq 28.3 or 31.9$)$ in both sample aliquots of the sub-adult female cheetah. This suggests that genomes equivalent to 10-100 tachyzoites were present in $10 \mu \mathrm{l}$ of the $100 \mu \mathrm{l}$ of DNA extracted from this faecal sample. No signal was observed in the sample of the adult female cheetah, although the IC real-time $\mathrm{PCR}$ revealed no inhibition.

\section{Characterisation of $18 S$ and ITS1 rDNA sequences of a Besnoitia sp.-like parasite}

The positive $B$. darlingi-like real-time PCR suggested either the presence of $B$. darlingi in the faeces of the positive cheetah-although this was unlikely because $B$. darlingi use marsupials as intermediate hosts, which are not present in Africa-or, most likely, the presence of oocysts of another, possibly not yet known, Besnoitia species. To identify this parasite, we partially characterised its rDNA using overlapping amplification products for parts of the $18 S$ rDNA, the ITS1 rDNA and parts of the $5.8 S$ rDNA (Fig. 1; Table 1; Additional file 1: Table S1). The sequences of the cloned amplicons were analysed by BLASTn with recording of the five top species hits using the BLASTn suite (Max Score). The amplicons of four different targets, using the primer pairs JS4-TIM11, 18S-5F-TIM11, BbGS4FBdanjoRev and BbGS5F-BbGS5R, revealed sequences related to the candidate of a Besnoitia species (Table 1). These were $B$. darlingi, B. neotomofelis, B. oryctofelisi, B. jellisoni, B. akodoni, B. besnoiti, B. bennetti, B. caprae and $B$. tarandi, with percent identities ranging up to $99.54 \%$ among the top species hits in BLASTn (Table 1; Besnoitia sp.-related). With the exception of the BbGS4F-BdanjoRev-cloned sequences, B. darlingi sequences (GenBank, EMBL, DDBJ, RefSeq) always ranked first (Table 1), which suggests that a parasite closely related to $B$. darlingi or $B$. darlingi-like parasites had been excreted as oocysts by the Namibian cheetah. The sequences of the JS4-TIM11 $(n=6), 18 \mathrm{~S}-5 \mathrm{~F}-$ TIM11 $(n=3)$ and BbGS4F-BdanjoRev $(n=3)$ clones, i.e. clones covering the ITS1 sequence, were aligned, and the consensus sequence was stored at GenBank (MW468050) using the parasite isolate designation "Besnoitia-acinonyx". The $B$. darlingi-like sequence amplified by BbGS5F-BbGS5R (i.e. a part of the $18 \mathrm{~S}$ rDNA) was also stored in GenBank (MW559556).

Some of the remaining sequences had only coccidian parasites among the first five species hits. However, these species hits were dominated by Cystoisospora spp., which may suggest that Cystoisospora spp. had been present in the faecal samples in addition to the $B$. darlingi-like parasites (Table 1; Coccidia-related).

\section{Phylogenetic relationships to "Besnoitia-acinonyx"}

Based on the ITS1 rDNA sequence, the possible phylogenetic relationships of the newly described species, represented by the DNA isolate (here termed "Besnoitiaacinonyx"), to other Besnoitia spp., namely B. darlingi, $B$. neotomofelis, B. oryctofelisi, B. akodoni, B. jellisoni and B. besnoiti, but also to $T$. gondii, $H$. heydorni, $H$. triffitae and $N$. caninum, were assessed. The ITS1 sequence placed "Besnoitia-acinonyx" between those of $B$. darlingi, $B$. darlingi-like parasites and B. besnoiti (Fig. 2). Estimates of evolutionary divergence revealed a close relationship to $B$. darlingi, B. neotomofelis, B. oryctofelisi, B. akodoni and $B$. jellisoni (pairwise distances $<0.1$; Table 2) and a larger distance to $B$. besnoiti (distance 0.234; Table 2). Among the remaining coccidia tested, T. gondii showed a higher distance to "Besnoitia-acinonyx" (0.595; Table 2) than $N$. caninum (0.544; Table 2). Interestingly, T. gondii and $N$. caninum showed a closer relationship to "Besnoitia-acinonyx" than to all remaining Besnoitia spp. except B. besnoiti (Table 2). In addition, B. besnoiti was closer to 
Table 1 The PCR analyses targeted nine overlapping regions of the 185 rDNA, internal transcribed spacer-1 rDNA and part of the 5.8S rDNA

\begin{tabular}{|c|c|c|c|}
\hline Relatedness of sequences & Amplification with primer pairs & $\begin{array}{l}\text { Number } \\
\text { of clones }\end{array}$ & $\begin{array}{l}\text { Top five species with highest identity and coverage in GenBank (number of } \\
\text { sequences per organism, percent coverage, percent identity) }\end{array}$ \\
\hline \multirow[t]{6}{*}{ Besnoitia sp.-related } & BbGS4F-BdanjoRev & 3 & $\begin{array}{l}\text { Besnoitia oryctofelisi }(1,99-100,98.58-99.01) \text {, B. darlingi (1,99-100, 98.31-98.73), } \\
\text { B. tarandi (1, 100, 97.85-98.17), B. besnoiti (7, 99-100, 97.85-98.17), B. bennetti } \\
(1,99-100,97.69-98.03)\end{array}$ \\
\hline & JS4-TIM11 & 3 & $\begin{array}{l}\text { Besnoitia darlingi }(3,82-90,93.60-94.20) \text {, B. oryctofelisi }(2,77-80,93.42-93.91) \text {, } \\
\text { B. caprae }(1,100,87.02-88.03), \text { B. besnoiti }(5,100,87.02-88.06), \text { B. akodoni (1, } \\
\text { 76-77, 92.52-92.97) }\end{array}$ \\
\hline & 18S-5F-TIM11 & 3 & $\begin{array}{l}\text { Besnoitia darlingi }(1,92,95.75-96.02) \text {, B. oryctofelisi }(1,89-90,95.93-96.19), B . \\
\text { besnoiti }(7,99-100,91.41-91.82), \text { B. tarandi }(1,96-97,91.32-91.72), \text { B. bennetti } \\
(1,93,91.04-91.46)\end{array}$ \\
\hline & JS4-TIM11 & 2 & $\begin{array}{l}\text { Besnoitia darlingi }(3,79-90,92.86-93.40), \text { B. oryctofelisi }(2,75-78,92.73-92.97), B . \\
\text { caprae }(1,100,86.44-86.81), \text { B. besnoiti }(5,100,86.44-86.81), \text { B. bennetti }(1,100 \text {, } \\
\text { 86.21-86.60) }\end{array}$ \\
\hline & JS4-TIM11 & 1 & $\begin{array}{l}\text { Besnoitia darlingi }(2,80-89,91.95-92.82), \text { B. oryctofelisi }(2,85-86,92.69-92.82), B . \\
\text { akodoni }(1,83,91.72), \text { B. neotomofelis }(1,83,90.72), \text { B. bennetti }(1,100,85.54)\end{array}$ \\
\hline & BbGS5F-BbGS5R & 2 & $\begin{array}{l}\text { Besnoitia darlingi }(2,99-100,99.31-99.54) \text {, B. oryctofelisi }(1,99-100,99.31-99.54) \text {, } \\
\text { B. jellisoni (1, 99-100, 99.31-99.54), B. besnoiti }(12,100,99.09-99.31) \text {, B. tarandi } \\
(2,100,98.86-99.31)\end{array}$ \\
\hline \multirow[t]{6}{*}{ Coccidia-related } & BbGS1F-BbGS1R & 6 & $\begin{array}{l}\text { Cystoisospora sp. ex. Aonyx cinereus (1, 99, 99.17-99.67), C. belli (8, 63, 99.17- } \\
\text { 99.67), C. ohioensis (4, 63-99, 99.00-99.50), C. suis (2, 63-99, 99.00-99.50), } \\
\text { Cystoisospora sp. (1, 63-99, 99.00-99.50) }\end{array}$ \\
\hline & BbGS4F-BbGS4R & 2 & $\begin{array}{l}\text { Cystoisospora belli }(5,100,99.66) \text {, C. timori }(1,100,99.66) \text {, C. cf. ohioensis }(1,100, \\
\text { 99.49), H. triffitae }(1,100,99.33) \text {, H. heydorni }(1,100,99.33)\end{array}$ \\
\hline & BbGS6F-BbGS6R & 2 & $\begin{array}{l}\text { Cystoisospora ohioensis (4, 97-100, 99.76-99.53), C. belli }(5,100,99.30-99.53), C . \\
\text { timori }(1,100,99.06), \text { C. canis }(2,97,99.76), \text { C. suis }(2,97,99.76)\end{array}$ \\
\hline & $\mathrm{BbGS} 2 \mathrm{~F}-\mathrm{BbGS} 2 \mathrm{R}$ & 1 & $\begin{array}{l}\text { Cystoisospora sp. ex. Aonyx cinereus }(1,100,100.00) \text {, C. canis }(2,100,100.00), C \text {. } \\
\text { ohioensis }(3,100,100.00) \text {, C. suis }(2,100,100.00) \text {, C. laidlawi }(1,100,100.00)\end{array}$ \\
\hline & BbGS3F-BbGS3R & 1 & $\begin{array}{l}\text { B. besnoiti }(4,100,99.81) \text {, B. darlingi }(1,100,99.81) \text {, T. gondii }(19,100,99.81), H \text {. } \\
\text { heydorni }(1,100,99.81) \text {, H. hammondi }(1,100,99.81)\end{array}$ \\
\hline & BbGS3F-BbGS3R & 1 & $\begin{array}{l}\text { Cystoisospora ohioensis }(4,100,99.81) \text {, C. suis }(2,100,99.81) \text {, C. belli }(2,100,99.81) \text {, } \\
\text { Cystoisospora sp. }(1,100,99.81) \text {, C. timori }(1,100,99.81)\end{array}$ \\
\hline \multirow[t]{4}{*}{ Unrelated to coccidia } & $\mathrm{BbGS6F-BbGS6R}$ & 1 & $\begin{array}{l}\text { Thecaphora spilanthes }(1,70,93.64) \text {, uncultured basidiomycete }(1,67,92.89) \text {, } \\
\text { Exobasidium rhododentri }(1,70,90.36) \text {, uncultured Ceriporiopsis }(1,72,89.44) \text {, } \\
\text { Exobasidium rostrupli }(1,70,90.07) \text {, }\end{array}$ \\
\hline & BbGS6F-BbGS6R & 1 & $\begin{array}{l}\text { Thecaphora spilanthes }(1,45,98.79) \text {, Arabidopsis lyrate }(1,56,99.09) \text {, Scyliorhinus } \\
\text { canicula }(1,34,99.09) \text {, uncultured archeon }(1,40,99.08) \text {, uncultured bacterium } \\
(4,40,99.08)\end{array}$ \\
\hline & BbGS4F-BbGS4R & 1 & $\begin{array}{l}\text { Helminthosporium hispanicum }(2,100,89.92) \text {, H. tiliae }(2,100,89.92) \text {, H. quercium } \\
(2,100,89.92), H \text {. austriacum }(2,100,89.92) \text {, H. velutium }(3,100,89.92)\end{array}$ \\
\hline & BbGS4F-BbGS4R & 1 & $\begin{array}{l}\text { Thecaphora saponariae }(1,75,99.65) \text {, Thecaphora amaranthi }(1,76,90.12) \text {, } \\
\text { Exobasidiomycetes sp. }(1,78,89.09) \text {, Tilletiopsis washingtonensis }(1,78,88.76) \text {, } \\
\text { Tilletiopsis sp. }(1,78,88.76)\end{array}$ \\
\hline
\end{tabular}

A variable number of plasmid clones per target was received and subsequently Sanger-sequenced. Sequences were not concatenated, but individually assessed by BLASTn. The top five hits of species using in BLASTn the option MaxScore are displayed. Due to the conserved primer regions, sequences of unrelated species, i.e. predominantly fungi, were identified in addition to sequences resembling sequences of coccidian parasite-related or Besnoitia sp.-related species

"Besnoitia-acinonyx" (0.234; Table 2) than to any other Besnoitia sp. examined (0.294-0.268; Table 2). Identities of the ITS1 rDNA of "Besnoitia-acinonyx" with B. darling $i$ and the $B$. darlingi-like parasites were $89.7-90.1 \%$ (B. darlingi), 89.7\% (B. oryctofelisi), 88.9\% (B. akodoni) and $86.9 \%$ (B. jellisoni and B. neotomofelis).

\section{Discussion}

In this study, we examined archived faecal samples of two free-ranging cheetahs from farmland in central Namibia. Coccidian parasites had been identified by coproscopy in these samples previously [19]. Using a coccidia-specific PCR, the microscopic observations were confirmed for both animals.

We originally expected $T$. gondii or $H$. hammondi in the cheetahs, as these parasites are known to use felids 

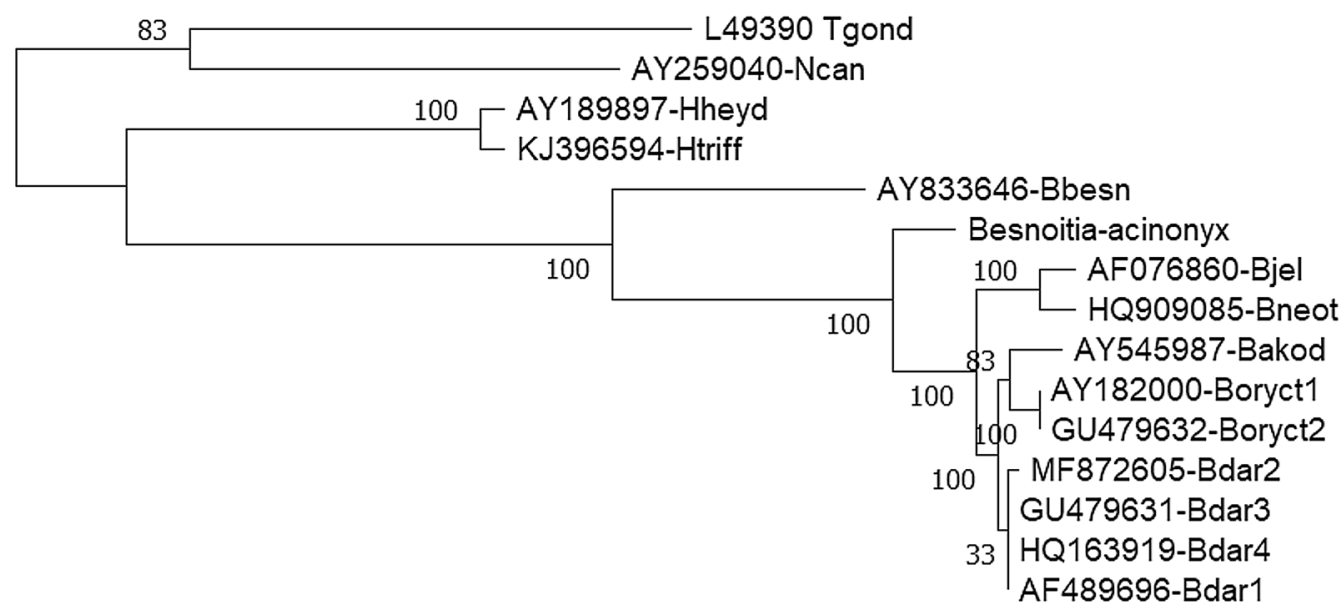

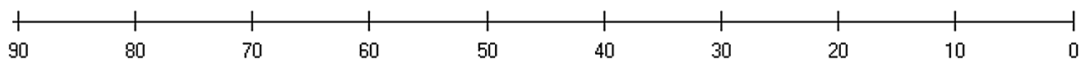

Fig. 2 GenBank sequences of Neospora caninum (Ncan; AY259040), Toxoplasma gondii (Tgond; ME49, L49390), Hammondia heydorni (Hheyd; AY189897), Hammondia triffitae (Htriff; KJ396594), Besnoitia besnoiti (Bbesn, AY833646), "Besnoitia-acinonyx" (MW468050; this study; Additional file 2: Text S1), B. jellisoni (Bjel; AF076860), B. neotomofelis (Bneot; HQ909085), B. akodoni (Bakod; AY545987), B. oryctofelisi \#1 (Boryct1; AY182000), B. oryctofelisi \#2 (Boryct2; GU479632), B. darlingi \#1 (Bdar1; AF489696), B. darlingi \#2 (Bdar2; MF872605), B. darlingi \#3 (Bdar3; GU479631) and B. darlingi \#4 (Bdar4, HQ163919) were subjected to evolutionary history analysis using the maximum parsimony (MP) method. The consensus tree inferred from the 6 most parsimonious trees is shown. Branches corresponding to partitions reproduced in $<50 \%$ trees are collapsed. The consistency index is 0.912 (0.866), the retention index is $0.910(0.910)$, and the composite index is 0.830 (0.788) for all sites and parsimony-informative sites (in parentheses). The MP tree was obtained using the subtree-pruning-regrafting algorithm [35] with search level 0 , in which the initial trees were obtained by the random addition of sequences (10 replicates). The tree is drawn to scale, with branch lengths calculated using the average pathway method [35] and are in the units of the number of changes over the whole sequence. The analysis involved 15 nucleotide sequences. All codon positions (1st, 2nd, 3rd, noncoding) were included. There were 425 positions in the final dataset. Evolutionary analyses were conducted in MEGA X [36]

as definitive hosts [37]. Antibodies against the tachyzoite stage of $B$. besnoiti had been detected in blue wildebeest (Connochaetes taurinus) and lions (Panthera leo) in Namibia by serology [17]. Thus, in addition, we suspected that $B$. besnoiti might be present in faecal samples of Namibian cheetahs because felids might be a definitive (and/or intermediate) host of B. besnoiti $[17,18]$. In southern Africa, the existence of $B$. besnoiti, which uses cattle as intermediate hosts, has long been known (summarised in [38]). Besnoitia besnoiti-like parasites have been previously isolated from or observed in prey animals of cheetah, such as blue wildebeest, impala (Aepyceros melampus) and kudu (Tragelaphus strepsiceros) in South Africa [39].

For reasons of completeness, DNA extracted from the faecal samples was also examined for N. caninum and $H$. heydorni, although these are parasites of dogs, dingoes, wolves or coyotes [27, 40], and for B. darlingi, which uses marsupials as intermediate hosts, as well as for $B$. darlingi-like parasites [16].

Using our previously developed real-time PCR, established to identify $B$. darlingi, $B$. neotomofelis, $B$. oryctofelisi, $B$. akodoni and $B$. jellisoni in intermediate and definitive hosts, we obtained positive results with two sample aliquots from one cheetah (Cq 28.3 and $\mathrm{Cq}$ 31.9). When this newly developed real-time PCR was first reported, we hypothesised that further $B$. darlingirelated parasites might exist worldwide and might be picked up by this PCR [16]. Since all $B$. darlingi-like parasites known so far have been detected in North or South America, we deemed it unlikely that the $B$. darlingi-like PCR signal that was observed in the faeces of the cheetah belonged to $B$. darlingi or one of the American $B$. darlingi-like parasites. Therefore, this study reports the first evidence for the existence of an additional Besnoitia sp. in southern Africa.

A part of the rDNA (18S rDNA) and in particular the ITS1 rDNA sequence of this parasite was characterised in more detail. In analogy to other coccidian parasites, such as $T$. gondii, we expected that the rDNA sequence would be present more than 100-fold in the genome of a single parasite organism [41], which makes the rDNA gene and particularly the ITS1 region a sensitive target for species identification. Since there were no purified oocysts from the faecal samples available, it was difficult to identify or amplify Besnoitia sp. DNA selectively from the plethora of organisms (most likely bacteria and fungi) present in the faecal samples. 


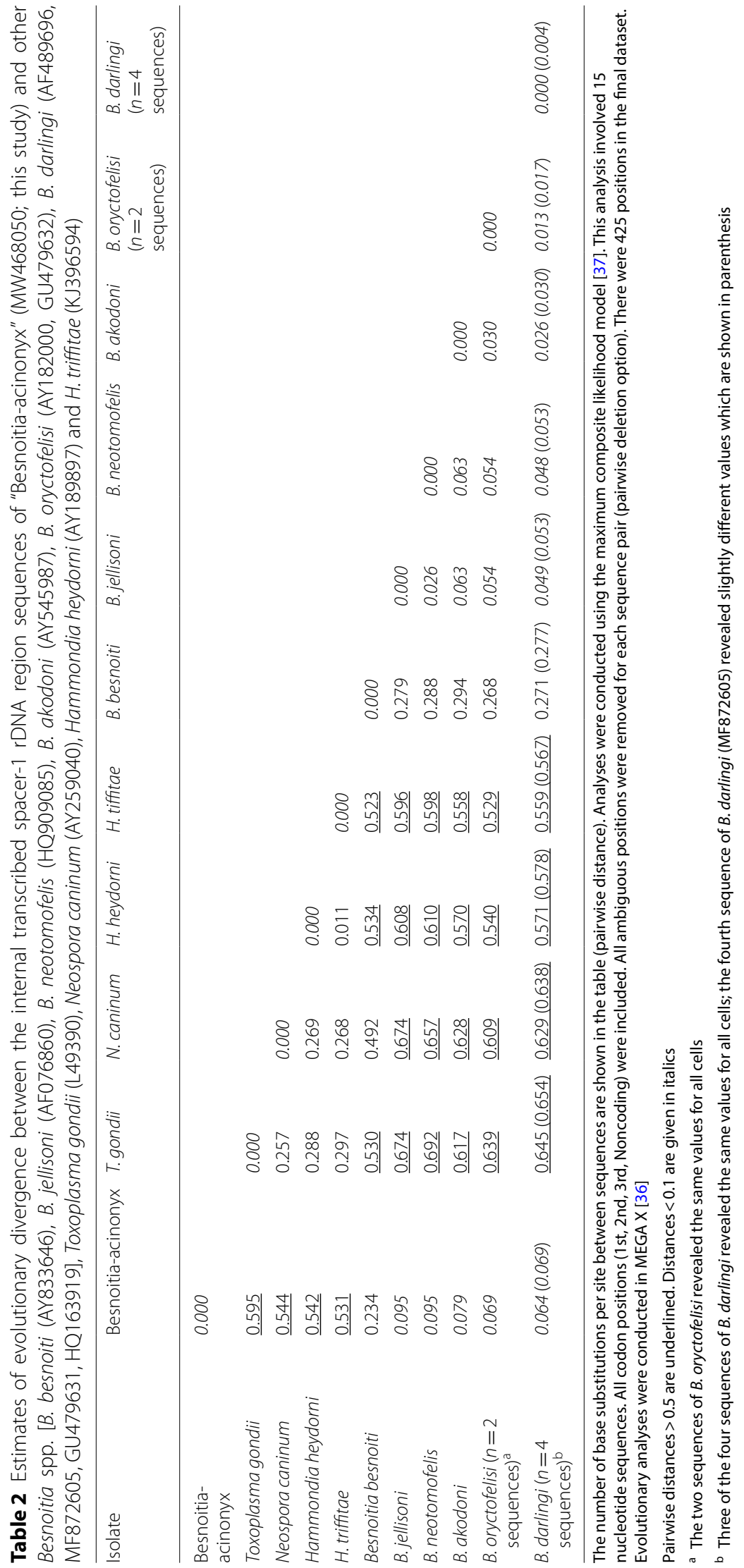


Our real-time PCR results suggested that genomes equivalent to $10-100$ tachyzoites were present in $10 \mu \mathrm{l}$ of the $100 \mu \mathrm{l}$ of DNA extracted from $200 \mathrm{mg}$ of the positive faecal sample. This corresponds to about 60-600 up to 500-5000 oocysts per gram faeces, depending on the proportion of sporulated oocysts (assuming 8 genomes in sporulated oocyts and only a single genome in unsporulated oocysts from the gut). Since oocysts were collected from the ampulla recti-and were therefore unsporulated-the estimate of 500-5000 oocysts per gram of faeces seems more realistic. This estimation is in accord with the number of 3600 oocysts with an approximate size of $18 \times 18 \mu \mathrm{m}$ per gram faeces recorded in the previous coproscopy study [19]. However, oocysts of $B$. darlingi-like parasites have an expected size of $10 \times 12 \mu \mathrm{m}$ (B. darlingi $[1,5]), 11 \times 12 \mu \mathrm{m}$ (B. oryctofelisi, $[1,2])$ or $13 \times 14 \mu \mathrm{m}$ (B. neotomofelis, [2]). Several scenarios are possible to explain this discrepancy. First, the oocysts of "Besnoitia-acinonyx" are $18 \times 18 \mu \mathrm{m}$ in size. Second, other coccidian parasites, probably Cystoisospora sp., were also present in the sample and oocysts with a diameter of 10-14 $\mu \mathrm{m}$ (expected for Besnoitia sp.) were overlooked. In addition to the oocyst sizes observed, the sequences of $18 S$ rDNA fragments amplified suggest that Cystoisospora sp. were also present in these faeces, which supports the second scenario. However, the observation of such sequences is not a final proof of the existence of Cystoisospora sp. because $18 S$ rDNA sequences are largely conserved and particular sequence fragments of the $18 S$ rDNA can belong to many different coccidian parasites [42]. Third, and a less likely scenario, it can be hypothesised that the observed "Besnoitia-acinonyx" DNA did not originate from oocysts, but from intermediate host stages in infected prey of the cheetah. Fourth, coprophagia as a source of the observed oocysts is very unlikely, as cheetahs display an extremely selective feeding behaviour and coprophagia has never been observed in this species [43]. Fifth, feeding from carcasses is also very rare in cheetahs [43]. Thus, future studies are necessary to isolate oocysts of this parasite from cheetahs to confirm that this species is the definitive host of "Besnoitia-acinonyx" and to determine the respective oocyst size of this B. darlingi-related parasite.

As several organisms (including other coccidia) may have been present in the faeces, we concentrated on sequences that belonged unambiguously to $B$. darlingilike parasites. The BdanjoRev primer [16], which had been applied in the $B$. darlingi real-time PCR, playedin combination with the BbGS4F primer [28] - a central role in the identification of the correct Besnoitia-like rDNA sequences [16]. Using the previously published primer pair JS4 [23] and TIM11 [29], as well as the newly established primer $18 \mathrm{~S}-5 \mathrm{~F}$ in combination with TIM11, we observed exclusively $B$. darlingi-like sequences, which we aligned and made available as a provisional rDNA sequence of "Besnoitia-acinonyx" (MW468050).

The ITS1 region of the rDNA Besnoitia spp. of New World marsupials, rodents and domestic rabbits show only a few differences $[5,44]$. The ITS 1 rDNA sequence of the Besnoitia sp. observed in the Namibian cheetah was similar to previously described ITS1 rDNA sequences, but differed from all $B$. darlingi and $B$. darlingi-like sequences described to date. Identities of the ITS1 rDNA of "Besnoitia-acinonyx" with $B$. darlingi and B. darlingi-like parasites were $\leq 90 \%$ (i.e. $89.7-90.1 \%$ [B. darlingi], 89.7\% [B. oryctofelisi], 88.9\% [B. akodoni] and $86.9 \%$ [B. jellisoni and B. neotomofelis]). Compared among each other, $B$. darlingi and the remaining $B$. darlingi-like parasites (namely B. oryctofelisi, B. akodoni, $B$. jellisoni and $B$. neotomofelis), each characterised by different intermediate host spectra, showed much higher identities in the ITS1 rDNA region, ranging from $92.9 \%$ to $98.3 \%$. Thus, it appears to be justified to conclude that the "Besnoitia-acinonyx" sequence belongs to a so far unknown Besnoitia sp. that most likely uses the cheetah as its definitive host. This view is supported further by identities among the ITS1 rDNAs of Besnoitia sp. of ungulates (namely B. besnoiti, B. tarandi, B. bennetti, $B$. caprae) which are almost $100 \%$ identical, but belong to clearly separate species.

Since no free-ranging marsupials exist in Africa, rodent or lagomorph species, which are prey for cheetahs, probably serve this parasite as intermediate hosts. In analogy to the South American B. oryctofelisi, lagomorphs, such as the Cape hare (Lepus capensis), the Savanna hare ( $L$. microtis) or the Scrub hare (L. saxatilis), may represent suitable intermediate hosts.

The ITS1 rDNA sequence of "Besnoitia-acinonyx" suggests a closer relationship to the American $B$. darlingi and $B$. darlingi-like parasites than to $B$. besnoiti, which infects cattle and probably also antelopes in southern Africa. This finding suggests that all B. darlingi or B. darlingi-like parasites, regardless of their American or African origin and their ability to infect marsupials or placental mammals, have a common ancestor, which evolved when the South American and the African continents were not yet disconnected, i.e. 100-200 million years ago. Most likely, this common ancestor evolved together with marsupial and placental mammalian animals, which started to separate also around this time [45]. Marsupial mammals are the closest living relatives to placental mammals, sharing a common ancestor that lived approximaely 130 million years ago [45]. 


\section{Conclusion}

Molecular analysis of a faecal sample revealed that Namibian cheetah (Acinonyx jubatus) is most likely a definitive host of a newly described Besnoitia species. This species is closely related to $B$. darlingi and other related Besnoitia spp. parasites of rodents and lagomorphs. Future studies are needed to identify its natural intermediate host in southern Africa, which most likely is a common prey of the Namibian cheetah. Hares, rabbits and rodents represent possible intermediate host candidates to be further examined.

\section{Abbreviations}

Cq: Quantification cycle; EGFP: Enhanced green fluorescent protein; ITS1: Internal transcribed spacer-1; MP: Maximum parsimony; rDNA: Ribosomal DNA.

\section{Supplementary Information}

The online version contains supplementary material available at https://doi. org/10.1186/s13071-021-04697-3.

Additional file 1: Table S1. Primer sequences used to amplify rDNA in two aliquots of a faecal sample of a Namibian cheetah with the aim to characterise an unknown Besnoitia sp.

Additional file 2: Text S1. Sequence alignment to assemble the ITS1 rDNA and part of the 185 and 5.85 rDNAs of a B. darlingi-like parasite (here called "Besnoitia-acinonyx") of Namibian cheetah (Acinonyx jubatus). The text file shows 12 amplicon-based sequences used to establish MW468050.

\section{Acknowledgements}

We would like to thank the Ministry of Environment, Forestry and Tourism in Namibia for permission to conduct research in their country and to the farmers of the Seeis conservancy for their collaboration and help. We are grateful to SK Heinrich, J Melzheimer and B Wasiolka for sample collections in the field and to F Webster and SC Martins Ferreira for the coproscopical analysis.

\section{Authors' contributions}

GS, BW and GÁC designed the study. BW, MJ, FR, PM and GS collected the data. MJ, MT and GS performed the experiments and analysed the samples. GS analysed the data. BW, PM, FR, MJ and GS interpreted the data. GS, BW, GÁC, $\mathrm{MJ}$ and FJC made major contributions to the writing of the manuscript. All authors read and approved the final manuscript.

\section{Funding}

Open Access funding enabled and organized by Projekt DEAL. MJ, FR, PM, FJC and GS are part of the TOXOSOURCES and MEmE consortia, supported by funding from the European Union's Horizon 2020 Research and Innovation programme under grant agreement No. 773830: One Health European Joint Programme. BW and GÁC are funded by the DFG Research Training Group (GRK) 2046 "Parasite Infections: From Experimental Models to Natural Systems", by the Messerli Foundation, Switzerland, and by the Leibniz Institute for Zoo and Wildlife Research, Germany.

\section{Availability of data and materials}

Data supporting the conclusions of this article are included within the article and its additional files. The raw datasets used and analysed for the present study are available from the corresponding author upon reasonable request.

\section{Declarations}

Ethics approval and consent to participate

All experimental procedures, including animal immobilisation and sample collection, were approved by the Internal Ethics Committee of the Leibniz Institute for Zoo and Wildlife Research (Leibniz-IZW) (permit number 200204-01) and authorised by the Ministry of Environment, Forestry and Tourism of Namibia (permit numbers 1514/2011 and 1689/2012). Samples were transported to Germany in full compliance with the Convention on International Trade in Endangered Species (CITES). All experiments were carried out in compliance with the approved guidelines of the IZW and the laws of Germany and Namibia.

\section{Consent for publication}

Not applicable.

\section{Competing interests}

The authors declare that they have no competing interests.

\section{Author details}

${ }^{1}$ Institute of Epidemiology, Friedrich-Loeffler-Institut, Federal Research Institute for Animal Health, Südufer 10, 17493 Greifswald-Insel Riems, Germany. ${ }^{2}$ Department of Wildlife Diseases, Leibniz Institute for Zoo and Wildlife Research, Alfred-Kowalke-Street 17, 10315 Berlin, Germany. ${ }^{3}$ Department of Evolutionary Ecology, Leibniz Institute for Zoo and Wildlife Research, Alfred-Kowalke-Street 17, 10315 Berlin, Germany.

Received: 12 February 2021 Accepted: 22 March 2021

Published online: 14 April 2021

\section{References}

1. Dubey JP, Sreekumar C, Lindsay DS, Hill D, Rosenthal BM, Venturini L, et al. Besnoitia oryctofelisi n. sp. (Protozoa: Apicomplexa) from domestic rabbits. Parasitology. 2003;126:521-39.

2. Dubey JP, Yabsley MJ. Besnoitia neotomofelis n. sp. (Protozoa: Apicomplexa) from the southern plains woodrat (Neotoma micropus). Parasitology. 2010;137:1731-47.

3. Smith DD, Frenkel JK. Besnoitia darlingi (Protozoa: Toxoplasmatinae): cyclic transmission by cats. J Parasitol. 1977;63:1066-71.

4. Smith DD, Frenkel JK. Besnoitia darlingi (Apicomplexa, Sarcocystidae, Toxoplasmatinae): transmission between opossums and cats. J Protozool. 1984;31:584-7.

5. Verma SK, Cerqueira-Cezar CK, Murata FHA, Lovallo MJ, Rosenthal BM, Dubey JP. Bobcats (Lynx rufus) are natural definitive host of Besnoitia darlingi. Vet Parasitol. 2017;248:84-9

6. Venturini L, Petruccelli M, Piscopo M, Unzaga JM, Venturini MC, Bacigalupe D, et al. Natural Besnoitia sp. infection in domestic rabbits from Argentina. Vet Parasitol. 2002;107:273-8.

7. Dubey JP, Sreekumar C, Rosenthal BM, Lindsay DS, Grisard EC, Vitor RW. Biological and molecular characterization of Besnoitia akodoni n. sp. (Protozoa: Apicomplexa) from the rodent Akodon montensis in Brazil. Parassitologia. 2003;45:61-70.

8. Ernst JV, Chobotar B, Oaks EC, Hammond DM. Besnoitia jellisoni (Sporozoa: Toxoplasmea) in rodents from Utah and California. J Parasitol. 1968:54:545-9.

9. Frenkel JK. Infections with organisms resembling Toxoplasma, together with the description of a new organism: Besnoitia jellisoni. Atti del VI Congr Intern Microbiol. 1953;5:426-37.

10. Frenkel JK. Besnoitia wallacei of cats and rodents: with a reclassification of other cyst-forming isosporoid coccidia. J Parasitol. 1977;63:611-28.

11. Wallace GD, Frenkel JK. Besnoitia species (Protozoa, Sporozoa, Toxoplasmatidae): recognition of cyclic transmission by cats. Science. 1975;188:369-71

12. Ito S, Tsunoda K, Shimura K. Life cycle of the large type of Isospora bigemina of the cat. Natl Inst Anim Health Q (Tokyo). 1978;18:69-82.

13. Mason RW. The discovery of Besnoitia wallacei in Australia and the identification of a free-living intermediate host. Z Parasitenkd. 1980;61:173-8. 
14. McKenna PB, Charleston WA. Coccidia (Protozoa: Sporozoasida) of cats and dogs. III. The occurrence of a species of Besnoitia in cats. N Z Vet J. 1980;28:120-2

15. Ng'ang'a CJ, Kanyari PW, Munyua WK. Isolation of Besnoitia wallacei in Kenya. Vet Parasitol. 1994;52:203-6.

16. Schares G, Dubey JP, Rosenthal B, Tuschy M, Bärwald A, Conraths FJ. Sensitive, quantitative detection of Besnoitia darlingi and related parasites in intermediate hosts and to assess felids as definitive hosts for known and as-yet undescribed related parasite species. Int J Parasitol Parasites Wildl. 2020;11:114-9.

17. Seltmann A, Schares G, Aschenborn OHK, Heinrich SK, Thalwitzer S, Wachter B, et al. Species-specific differences in Toxoplasma gondii, Neospora caninum and Besnoitia besnoiti seroprevalence in Namibian wildlife. Parasites Vectors. 2020;13:7.

18. Alvarez-Garcia G, Frey CF, Mora LM, Schares G. A century of bovine besnoitiosis: an unknown disease re-emerging in Europe. Trends Parasitol. 2013;29:407-15

19. Seltmann A, Webster F, Martins Ferreira SC, Czirják GÁ, Wachter B. Agespecific gastrointestinal parasite shedding in free-ranging cheetahs (Acinonyx jubatus) on Namibian farmland. Parasitol Res. 2019:118:851-9.

20. Heinrich SK, Hofer H, Courtiol A, Melzheimer J, Dehnhard M, Czirják GÁ, et al. Cheetahs have a stronger constitutive innate immunity than leopards. Sci Rep. 2017;7:44837.

21. Ho MSY, Barr BC, Marsh AE, Anderson ML, Rowe JD, Tarantal AF, et al. Identification of bovine Neospora parasites by PCR amplification and specific small-subunit rRNA sequence probe hybridization. J Clin Microbiol. 1996;34:1203-8.

22. Schares G, Globokar Vrhovec M, Tuschy M, Joeres M, Bärwald A, Koudela $B$, et al. A real-time quantitative polymerase chain reaction for the specific detection of Hammondia hammondi and its differentiation from Toxoplasma gondii. Parasites Vectors. 2021;14:78.

23. Slapeta JR, Koudela B, Votypka J, Modry D, Horejs R, Lukes J. Coprodiagnosis of Hammondia heydorni in dogs by PCR based amplification of ITS 1 rRNA: differentiation from morphologically indistinguishable oocysts of Neospora caninum. Vet J. 2002;163:147-54

24. Schares G, Pantchev N, Barutzki D, Heydorn AO, Bauer C, Conraths FJ. Oocysts of Neospora caninum, Hammondia heydorni, Toxoplasma gondii and Hammondia hammondi in faeces collected from dogs in Germany. Int J Parasitol. 2005;35:1525-37.

25. Abel J, Schares G, Orzeszko K, Gasser RB, Ellis JT. Hammondia isolated from dogs and foxes are genetically distinct. Parasitology. 2006;132:187-92.

26. Schares G, Heydorn AO, Cüppers A, Conraths FJ, Mehlhorn H. Hammondia heydorni-like oocysts shed by a naturally infected dog and Neospora caninum NC-1 cannot be distinguished. Parasitol Res. 2001;87:808-16.

27. Gjerde B, Dahlgren SS. Hammondia triffittae n. comb. of foxes (Vulpes spp.): biological and molecular characteristics and differentiation from Hammondia heydorni of dogs. Parasitology. 2011;138:303-21.

28. Schares G, Basso W, Majzoub M, Cortes HC, Rostaher A, Selmair J, et al. First in vitro isolation of Besnoitia besnoiti from chronically infected cattle in Germany. Vet Parasitol. 2009;163:315-22.

29. Payne S, Ellis J. Detection of Neospora caninum DNA by the polymerase chain reaction. Int J Parasitol. 1996;26:347-51.

30. Talabani H, Asseraf M, Yera H, Delair E, Ancelle T, Thulliez P, et al. Contributions of immunoblotting, real-time PCR, and the Goldmann-Witmer coefficient to diagnosis of atypical toxoplasmic retinochoroiditis. J Clin Microbiol. 2009;47:2131-5.

31. Legnani S, Pantchev N, Forlani A, Zini E, Schares G, Balzer J, et al. Emergence of cutaneous neosporosis in a dog receiving immunosuppressive therapy: molecular identification and management. Vet Dermatol. 2016;27:49-e14

32. Schares G, Maksimov A, Basso W, More G, Dubey JP, Rosenthal B, et al. Quantitative real time polymerase chain reaction assays for the sensitive detection of Besnoitia besnoiti infection in cattle. Vet Parasitol. 2011;178:208-16

33. Constantin EM, Schares G, Grossmann E, Sauter K, Romig T, Hartmann S. Studies on the role of the red fox (Vulpes vulpes) as a potential definitive host of Neospora caninum. Berl Munch Tierarztl Wochenschr. 2011;124:148-53.

34. Hoffmann B, Depner K, Schirrmeier H, Beer M. A universal heterologous internal control system for duplex real-time RT-PCR assays used in a detection system for pestiviruses. J Virol Methods. 2006;136:200-9.

35. Nei M, Kumar S. Molecular evolution and phylogenetics. New York: Oxford University Press; 2000

36. Kumar S, Stecher G, Li M, Knyaz C, Tamura K. MEGA X: molecular evolutionary genetics analysis across computing platforms. Mol Biol Evol. 2018:35:1547-9.

37. Dubey JP. Toxoplasmosis of animals and humans. 2nd ed. Boca Raton: CRC Press; 2010.

38. Pols JW. Studies on bovine besnoitiosis with special reference to the aetiology. Onderstepoort J Vet Res. 1960;28:265-356.

39. Bigalke RD, van Niekerk JW, Basson PA, McCully RM. Studies on the relationship between Besnoitia of blue wildebeest and impala, and Besnoitia besnoiti of cattle. Onderstepoort J Vet Res. 1967;34:7-28.

40. Dubey JP, Hemphill A, Calero-Bernal R, Schares G. Neosporosis in animals. Boca Rotan: CRC Press; 2017.

41. Guay JM, Huot A, Gagnon S, Tremblay A, Levesque RC. Physical and genetic mapping of cloned ribosomal DNA from Toxoplasma gondii: primary and secondary structure of the 5 S gene. Gene. 1992;114:165-71.

42. Ogedengbe ME, Ogedengbe JD, Whale JCE, K., Juarez-Estrada MA, Barta JR, Molecular phylogenetic analyses of tissue coccidia (sarcocystidae; apicomplexa) based on nuclear 18s RDNA and mitochondrial COI sequences confirms the paraphyly of the genus Hammondia. Parasitology Open. 2016;2:1-16.

43. Caro TM. Cheetahs of the Serengeti plains: group living in an asocial species. Chicago: The University Press; 1994.

44. Olias P, Schade B, Mehlhorn H. Molecular pathology, taxonomy and epidemiology of Besnoitia species (Protozoa: Sarcocystidae). Infect Genet Evol. 2011;11:1564-76.

45. Nilsson MA, Churakov G, Sommer M, Tran NV, Zemann A, Brosius J, et al. Tracking marsupial evolution using archaic genomic retroposon insertions. PLoS Biol. 2010:8:e1000436.

\section{Publisher's Note}

Springer Nature remains neutral with regard to jurisdictional claims in published maps and institutional affiliations.

Ready to submit your research? Choose BMC and benefit from

- fast, convenient online submission

- thorough peer review by experienced researchers in your field

- rapid publication on acceptance

- support for research data, including large and complex data types

- gold Open Access which fosters wider collaboration and increased citations

- maximum visibility for your research: over 100M website views per year

At $\mathrm{BMC}$, research is always in progress.

Learn more biomedcentral.com/submissions 